\title{
A Pilot Study on the Mediating Effect of Job Embeddednesss on the Relationship between Quality of Work Life and Organizational Commitment
}

\author{
Musa, Leah ${ }^{1}$, Garba, Bala Bello ${ }^{2}$, Aliyu, Muktar Daneji ${ }^{3}$ \\ ${ }^{1}$ Department of Business Administration Federal University, Wukari, Nigeria \\ ${ }^{2,3}$ Department of Business Administration and Entrepreneurship Bayero University Kano, Nigeria
}

\begin{abstract}
The purpose of this paper is to examine a few sample data on the impact of quality of work life on organizational commitment with the mediating effect of job embeddedness in higher institutions of learning in Taraba State, Nigeria. A survey research was conducted with some questionnaire distributed. Thus, content and face validity, reliability and data normality are considered, after analyzing the data some items that correlated low with other items were deleted, in whichthe reliability of the scale is improved. The result showed that the Cronbach's Alpha is above the minimum threshold, It is therefore concluded that the items are reliable for future research and it is recommended that the items can be used for future studies.
\end{abstract}

\section{INTRODUCTION}

$\mathrm{H}$ uman resource management has taken a new direction from the traditional role of only recruiting process and administrative roles to maximizing the productivity of an organization by enhancing the efficiency of its workforces. This is because they supervise the most essential factor of an effective organization. The dynamics in the business world necessitate the importance of ensuring that the employees are not only selected and well placed, but they have an enabling environment to succeed (Singh \& Gupta, 2015). Organization maintained its stability in terms of productivity, financial viability and employee commitment when organizations can recruit, train, retrain and retain skilled individuals (Faloye, 2014). Organizational commitment is the individual psychological attachment to the organization, it lowers the level of intention to leave and gives higher level of productivity (Medhi, 2021; Eberman, Mazerolle \& Eason, 2019; Frontinha, Eason, \& Van 2019; Yousef, 2017).

Organizational commitment has been an essential factor in determining the success of an organization, when there is a constant decrease in productivity then there is a problem in commitment. Organizational commitment is the main factor in maintaining and increasing productivity, it also reduces turnover rate. Thus, decrease in productivity and increase in turnover rate signal problem of organizational commitment (Rusdiyanto, 2020, Jonathan, 2019, Latham, Borgogni \& Petitta 2018). Lack of organizational commitment gives negative effect on employee productivity and turnover rate which to a large extent contributes immensely to the failure of organization (Da Silva, Castro, Dos-Santos \&Neto, 2018;
Dechawatanapaisal, 2018; Cesario, \& Chambel, 2017; Babalola, Stouten \& Euwema, 2016; Igbaekemen \& Idowu 2014).

Quality of work life is the workplace strategies, operations and environment that promote and maintain employee satisfaction with an aim to improving working conditions for employees and organizational effectiveness for employers (Owolabi, 2018). The basic idea of quality of work life involves employee learning capability and organization environment without which jobs become threatened; there is insecurity, and increased levels of employee dissatisfaction. Quality of work life encompasses working conditions, financial and non-financial benefits and management behavior towards workers. Workers unrests often have to do with workers quality of life,the work life of workers is as important as their personal lives and their satisfaction and contentment in both aspects of life is very important to keep their lives and organization as well (Owolabi, 2018). Quality of work life seeks to create a culture of work commitment in organizations and society at large so as to ensure higher productivity and greater job satisfaction of the employees. It is the degree to which members of a work organization are able to satisfy important personnel needs through their experience in the organization. Quality of work life (QWL) is a dynamic multidimensional construct that includes concepts such as job security, reward systems, training and career advancement opportunities and participation in decision making. The concept of quality of work-life is a comprehensive term that includes work ethics and several facets of working conditions, measures for working conditions, employees' satisfaction, and efficiency in production. Sirgy, Efraty, Siegel, and Lee (2001) define quality of work life as employee satisfaction with a variety of needs by means of resources, activities, and outcomes stemming from participation in the workplace.

Over the past decade, increasing research attention has focused on embeddedness, the idea that individuals may become engrossed in their organization to be inseparable (Mitchell, Holtom, Lee, Sablynski, \& Erez, 2001). Mitchell et al. (2001) introduced the job embeddedness concept focusing narrowly to explain why people stay in their jobs. Job embeddedness indicates decisions to participate broadly and directly, and it focuses beyond dissatisfaction related leaving 
(Lee et al., 2004). Job embeddedness refers to a broad set of influences on an employee's decision to stay on the job (Holtom, Mitchell \& Lee, 2006). These influences include onthe job factors such as bonds with colleagues and the fit between one's skills and what the job demands,in addition, it includes off-the-job factors. Some examples of off-the-job factors are personal and community commitments (Holtom, Mitchell \& Lee, 2006). Based on Empirical studies it was discovered that people that are embedded in their jobs are less likely to quit than those who are not embedded. Employees who feel strongly embedded and committed may define their relationships with their employers as long-term relationships, as opposed to employees who have lower levels of embeddedness and commitment to their organizations (Heymann 2010; Mallol et al 2007; Mitchell et al 2001).

\subsection{Problem Statement}

The role of organizational commitment in today's business world cannot be over emphasized because it is an important factor that determines the success of an organization, thus, no organization can perform to its peak unless each employee is committed to the organizations objectives and perform as an active member of a team. Organizational commitment among staff is key as employees that are committed would remain attached to the organization and give in their best. Human resources are considered the main factor that makes up an organization without them nothing in the organization would get done.

The concern in quality of work life is not only to improve life at work but also life outside work; it is nothing rather than having a work environment where an employee's accomplishments become more important. QWL is not a unitary concept, but a multidimensional construct that has incorporated a variety of interrelated factors, researchers explained that what constitutes quality of work life depends on the environment and the industry where the study is conducted (Kwahar \& Iyorstuun). This is a complex problem, however, because it is difficult to isolate and identify the attributes which affect the quality of working life in all employees, because to balance between an employee's work demands and outside interests or pressures entails a thorough search to understand what employees actually need, knowing well that what appeals to one might not be applicable to other (Oludayo, Falola, Ahaka, \& Fatogun). In view of these perculiarities the paper used remuneration and benefits, job security and job career satisfaction, training and opportunity for personal autonomy, homework balanceas construct of quality of work life, job embeddedness as mediating variable and organizational commitment as dependent variable and carried out empirical pilot test in the context of higher institutions in Taraba State,Nigeria.

According to Cadete (2017) pilot study is carried out to determine the feasibility of research design. Polit and Beck (2017) added that it is also to prevent the occurrence of fatal flaws in a study that is costly in time and money. It is important to also generate lessons to inform subsequent studies. Hence, the aim of this study is toidentify potential problem areas and deficiencies in research instruments and protocol prior to the implementation during the full study, so as to get information whether a full scale study is feasible and list any recommended amendments to the design of the future study.

\section{LITERATURE REVIEW}

\subsection{Organizational Commitment}

The meaning of organizational commitment was first provided by Whyte in 1956. He explains it thus: "a man of organization not only works for the organization, but he also commits himself to the organization, and feels as if he belongs to it" (Whyte, 1956:143). After Whyte, many researchers such as Mowday, Steers, Becker, Allen, and Meyer have studied organizational commitment and this has made it an important subject in the area of organizational studies. Organizational commitment is one of the basic concepts that describe the relationship between an employee and an organization. Along with such concepts as work commitment and job satisfaction, it has been one of the leading research subjects for over 30 years.

The idea of organizational commitment is considered as an old notion due to a lot of changes and fluctuations in the 21st century, such as globalization, technological development and other reasons, and an outdated term. Commitment is the feeling of loyalty that employees have towards the organization that they work for, which largely depends on the extent to which they believe in the values and aims of the organization and feel personally involved in the task of making the organization successful. Torrington (2005) explains that commitment is a two way process which the organization itself has to initiate. This can be done by creating a clear employer brand and group identity so that the right people are recruited by the organization, and ensuring that the values of its brand image are delivered, by treating employees fairly and maintaining trust.

Allen and Meyer (1990) developed an early model that has received considerable attention on the concept of organizational commitment. The three-component model they advocated was based on their observation that existing definitions of commitment at that time reflected at least three distinct themes: an affective emotional attachment towards an organization (affective commitment); the recognition of costs associated with leaving an organization (continuance commitment); and a moral obligation to remain with an organization (normative commitment). They also argued that one of the most important reasons for distinguishing among the different forms of organizational commitment was that they have very different implications for behavior. Although all three forms tend to bind employees to the organization, and therefore relate negatively to turnover, their relations with other types of work behavior can be quite different (Meyer et al., 2002). Strong commitment brings desired effects in the organization such as low staff absenteeism and fluctuation, high productivity as well as determination of dispositional and 
situational attributions contributing to strong commitment development (Meyer, et al., 2002).

\subsection{Quality of Work Life $(Q W L)$}

The concept of quality of work life (QWL) was first launched by Davis (1973) at the "43rd American Assembly on the Changing World of Work" at Columbia University. It was reported by researchers who participated at the event that improving the place, the organization, and the nature of work can lead to better work performance and a better quality of life in the society (Wyatt \& Wah, 2001; Sadique, 2003; Islam \& Siengthai, 2009). Hackman and Oldham (1974) suggested that an individual's psychological growth needs should be addressed in any worthwhile endeavour to increase quality of work life. They refer to it as a philosophy, a set of principles, which holds that people are the most important resource in the organization as they are trustworthy, responsible and capable of making valuable contribution and they should be treated with dignity and respect.Quality of human resources hinge on the quality of work life obtainable through the organization, the concern in quality of work life is not only to improve life at work but also life outside work; it is nothing rather than having a work environment where an employee's accomplishments become more important.Quality of work life (QWL) is a dynamic multidimensional construct that includes concepts such as job security, reward systems, training and career advancement opportunities and participation in decision making. The concept of quality of work-life is a comprehensive term that includes work ethics and several facets of working conditions, measures for working conditions, employees' satisfaction, and efficiency in production. Sirgy, Efraty, Siegel, and Lee (2001) define quality of work life as employee satisfaction with a variety of needs by means of resources, activities, and outcomes stemming from participation in the workplace. Quality of work life also entails the verity of efforts to improve productivity through improvement in humans and it seeks organizational effectiveness through enhancement of human dignity and growth (Allen, 2001). It provides healthier, satisfied and productive employees, which in turn provides efficient and profitable organization (Sadique 2003).

\subsection{Job Embeddedness Theory}

The theory was first developed by Mitchell and colleagues to better explain turnover behavior. They referred to a feeling of being entrenched, stuckness to the job, or a net or a web in which an individual can become stuck (Mitchell et al., 2001). That is, job embeddedness encompasses the total forces on an individual that cause the person to remain at his/her current job. Since then, job embeddedness has been empirically demonstrated to impact work-related behaviors such as turnover, commitment, performance, absenteeism and citizenship behaviors (Lee, Mitchell, Sablynski, \& Burton, 2004; Ng \& Feldman, 2009). Job embeddedness is a specific type of embeddedness and represents a large range of factors that influence a person's relationship with a job and organization. Job embeddedness theory developed as a reaction to perceived deficiencies within traditional turnover theory dating back to March and Simon (1958). Turnover theory tends to look at attitudes such as job satisfaction and organizational commitment and whether or not there are job alternatives in determining whether a person will leave the organization. On the other hand, job embeddedness looks at a broader range of work and non-work factors for a more complete view of why people stay with organizations.

\section{METHODOLOGY}

Considering the fact that this study is a pilot study, a small sample is randomly selected based on the recommendation of Malhora (2008); Gorondutse and Hillman (2012) that the sample size for pre-test is usually few $10 \%$ of the total number, but it might be increased substantially if the test involves several stages. Hence, a total of 120 copies of the questionnaire were distributed to academic staff of higher educational institutions and 80 were completed and returned for the test. The constructs are measured thus; quality of work life measures by Kwahar \& Iyorstuun, Job embeddedness by Zhang, Fried \& Griffeth (2012) and organizational commitment measures by Allen \& Meyer (1990). Thus, the conceptual frame work;
Independable variable

\begin{tabular}{l|}
\hline Quality of Work \\
Life
\end{tabular}

Mediating variable

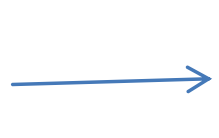

Dependable variable

\section{Job Embeddedness}

\section{Organizational \\ Commitment}

\section{DATA ANALYSIS AND FINDINGS}

To help in establishing the validity of the measurement instruments, exploratory factor analysis (EFA) was conducted in two phases in two models. Model 1 assessed the validity of the dimensions of quality of work life while Model 2 assessed the validity of the mediator and dependent variable, whether they demonstrate adequate discriminant validity.

\section{Evaluation of Reliability and Validity}

Phase 1

The dataset was tested for suitability of factor analysis which involved assessing the Kaiser-Meyer-Olking (KMO) Measure of Sampling Adequacy and the Bartlett's Test of Sphericity. In Model $1(\mathrm{KMO}=0.805)$ and Model $2(\mathrm{KMO}=0.813)$, the calculated KMO exceeded the recommended minimum of 0.6 
(Kaiser, 1974) while the Bartlett's Test of Sphericity (Bartlett, 1954) reached statistical significance (Model 1: chi-square $=$ $762.164, d f=253, \mathrm{p}<0.001 ;$ Model 2: chi-square $=657.153$, $d f=120, \mathrm{p}<0.001)$, supporting the factorability of the correlation matrix (see Table 1 below).

Table 1: KMO and Bartlett's Test of Sphericity

\begin{tabular}{|c|c|c|c|c|}
\hline Model & $\begin{array}{c}\text { Kaiser-Meyer-Olkin } \\
\text { Measure of Sampling } \\
\text { Adequacy }\end{array}$ & $\begin{array}{c}\text { Bartlett's Test of } \\
\text { Sphericity }\left(\chi^{2}\right)\end{array}$ & Sig. & $D f$ \\
\hline 1 & .805 & 762.164 & .000 & 253 \\
\hline 2 & .813 & 657.153 & .000 & 120 \\
\hline
\end{tabular}

Phase 2

Exploratory factor analysis was then conducted using the parameters. The extraction method was Principal Components Analysis with eigenvalues above 1.000 and supported by the Scree Plot. To aid in the interpretation of these extracted factors, Varimax Rotation with Kaiser Normalization was performed with loadings less than 0.40 omitted to improve clarity (Tabachnik \& Fidell, 2007). These parameters were implemented in both Model 1 and Model 2.

\section{Model 1}

The EFA PCA result revealed the presence of five factors with eigenvalues above 1 but the Scree Plot indicated the retention of four factors that relatively depicted the presence of relatively simple structure (Thurstone, 1947). The Component 5 was subsequently removed. All the five items of the Home-Work Balance loaded on Component 1 while for Job Security and Career Satisfaction 6-items loaded on Component 2. However, one item of Job Security and Career Satisfaction, JSCS3 loaded on Component 5, and was subsequently deleted; hence Job Security and Career Satisfaction resulted in five items.

Remuneration and Benefits items loaded on Component 3. One item of the Remuneration and Benefits items (RB3) was also deleted making the variable 6-items. The item was deleted because it loaded on Component 5. Lastly, Training and Opportunity for Personal Autonomy items loaded cleanly on Component 4 (Table 2). The four factors explained a total of $64.738 \%$ of the total variance explained (Table 3 ). Component 1 accounted for $19.522 \%$ of the variance followed by Component 2 (14.356\%), Component 3 (12.087\%), and Component 4 (11.540\%).

Further check of validity were conducted by calculating the Average Variance Extracted (AVE) and the Composite Reliability (CR). AVE measures the level of variance captured by a construct versus the level due to measurement error. AVE values above 0.5 (Hair, Hult, Ringle\&Sarstedt, 2014) are acceptable. On the other hand CR is a less biased estimate of Cronbach's Alpha. A minimum value of 0.7 is recommended for CR (Hair et al., 2014). Going by these recommendations, the values for AVE were 0.623, 0.560, 0.541 and 0.818 while for CR the values were $0.863,0.867$, 0.711 and 0.942 for Home-Work Balance, Job Security and
Career Satisfaction, Remuneration and Benefits and Training and Opportunities for Personal Autonomy respectively. All the values were above the minimum threshold and therefore, valid and reliability. The Cronbach's alpha calculated was found to be also above the minimum threshold of 0.70 (Nunnally, 1978) giving that the values were 0.721, 0.707, 0.729, and 0.713 for Home-Work Balance, Job Security and Career Satisfaction, Remuneration and Benefits and Training and Opportunities for Personal Autonomy respectively.

Table 2: Rotated Component Matrix

\begin{tabular}{|c|c|c|c|c|c|c|c|}
\hline & \multicolumn{4}{|c|}{ Component } & & & \\
\hline & 1 & 2 & 3 & 4 & $\begin{array}{c}\mathrm{AV} \\
\mathrm{E}\end{array}$ & $\mathrm{CR}$ & A \\
\hline HWB4 & .846 & & & & .654 & .904 & .905 \\
\hline HWB5 & .824 & & & & & & \\
\hline HWB2 & .817 & & & & & & \\
\hline HWB3 & .782 & & & & & & \\
\hline HWB1 & .774 & & & & & & \\
\hline JSCS5 & & 0.843 & & & .507 & .834 & .703 \\
\hline JSCS4 & & 0.768 & & & & & \\
\hline JSCS2 & & 0.764 & & & & & \\
\hline JSCS6 & & 0.575 & & & & & \\
\hline JSCS 1 & & 0.568 & & & & & \\
\hline RB3 & & & .773 & & .531 & .824 & .835 \\
\hline RB2 & & & .743 & & & & \\
\hline RB1 & & & .731 & & & & \\
\hline RB5 & & . & .576 & & & & \\
\hline RB4 & & & .573 & & & & \\
\hline RB7 & & & .558 & & & & \\
\hline TOPA5 & & & & 0.797 & .500 & .832 & .829 \\
\hline TOPA1 & & & & 0.731 & & & \\
\hline TOPA4 & & & & 0.698 & & & \\
\hline TOPA2 & & & & 0.691 & & & \\
\hline TOPA3 & & & & 0.606 & & & \\
\hline & & & & & & & \\
\hline
\end{tabular}


International Journal of Research and Innovation in Social Science (IJRISS) |Volume V, Issue XI, November 2021||ISSN 2454-6186

\begin{tabular}{|c|c|c|c|c|l|l|l|}
\hline $\begin{array}{c}\text { Eigenvalu } \\
\text { es }\end{array}$ & 7.549 & 2.889 & $\begin{array}{c}1.79 \\
6\end{array}$ & 1.342 & & & \\
\hline $\begin{array}{c}\% \text { of } \\
\text { variance }\end{array}$ & $19.5 \%$ & $\begin{array}{c}14.4 \\
\%\end{array}$ & $\begin{array}{c}12.1 \\
\%\end{array}$ & $11.5 \%$ & & & \\
\hline
\end{tabular}

Extraction Method: Principal Component Analysis.

Rotation Method: Varimax with Kaiser Normalization

a. Rotation converged in 8 iterations.

\begin{tabular}{|c|c|c|c|c|c|c|c|c|c|}
\hline \multirow{2}{*}{ Component } & \multicolumn{3}{|c|}{ Initial Eigenvalues } & \multicolumn{3}{|c|}{ Extraction Sums of Squared Loadings } & \multicolumn{3}{|c|}{ Rotation Sums of Squared Loadings } \\
\hline & Total & $\begin{array}{c}\% \text { of } \\
\text { Variance }\end{array}$ & Cumulative $\%$ & Total & $\begin{array}{c}\% \text { of } \\
\text { Variance }\end{array}$ & Cumulative $\%$ & Total & $\begin{array}{c}\% \text { of } \\
\text { Variance }\end{array}$ & Cumulative \% \\
\hline 1 & 7.549 & 32.822 & 32.822 & 7.549 & 32.822 & 32.822 & 4.490 & 19.522 & 19.522 \\
\hline 2 & 2.889 & 12.559 & 45.381 & 2.889 & 12.559 & 45.381 & 3.302 & 14.356 & 33.877 \\
\hline 3 & 1.796 & 7.810 & 53.191 & 1.796 & 7.810 & 53.191 & 2.780 & 12.087 & 45.964 \\
\hline 4 & 1.342 & 5.833 & 59.024 & 1.342 & 5.833 & 59.024 & 2.654 & 11.540 & 57.503 \\
\hline 5 & 1.314 & 5.714 & 64.738 & 1.314 & 5.714 & 64.738 & 1.664 & 7.235 & 64.738 \\
\hline 6 & .983 & 4.275 & 69.013 & & & & & & \\
\hline 7 & .932 & 4.050 & 73.063 & & & & & & \\
\hline 8 & .859 & 3.736 & 76.799 & & & & & & \\
\hline 9 & .726 & 3.158 & 79.956 & & & & & & \\
\hline 10 & .700 & 3.043 & 83.000 & & & & & & \\
\hline 11 & .524 & 2.280 & 85.279 & & & & & & \\
\hline 12 & .466 & 2.028 & 87.307 & & & & & & \\
\hline 13 & .449 & 1.951 & 89.258 & & & & & & \\
\hline 14 & .424 & 1.843 & 91.101 & & & & & & \\
\hline 15 & .363 & 1.580 & 92.682 & & & & & & \\
\hline 16 & .309 & 1.343 & 94.025 & & & & & & \\
\hline 17 & .295 & 1.280 & 95.305 & & & & & & \\
\hline 18 & .272 & 1.181 & 96.486 & & & & & & \\
\hline 19 & .223 & .968 & 97.453 & & & & & & \\
\hline 20 & .182 & .791 & 98.245 & & & & & & \\
\hline 21 & .157 & .682 & 98.927 & & & & & & \\
\hline 22 & .144 & .625 & 99.552 & & & & & & \\
\hline 23 & .103 & .448 & 100.000 & & & & & & \\
\hline
\end{tabular}

\section{Model 2}

The EFA PCA result revealed the presence of four factors with eigenvalues above 1 but the Scree Plot indicated the retention of two factors that relatively depicted the presence of relatively simple structure (Thurstone, 1947). Component 3 and Component 4 were subsequently removed. Eight items of Organizational Commitment and Job Embeddedness loaded on Component 1 and Component 2 respectively. This implies that one item of Job Embeddedness (JE6) and two items of Oganizational Commitment (OC1 and OC2) were removed. While the JE6 loaded on Component 3, OC1 and OC2 loaded on Component 4. Hence the EFA produced a two-factor component structure consisting of Organizational Commitment and Job Embeddedness.
The two factors explained a total of $55.140 \%$ of the total variance explained (Table 5). Component 1 accounted for $30.054 \%$ of the variance followed by Component 2 $(20.086 \%)$. Further check of validity as indicated by AVE and the CR were as follows: for Organizational Commitment, AVE and CR were 0.629 and 0.912 while for Job Embeddedness, the values were 0.527 and 0.887 respectively (see Table 4). The calculated Cronbach's alpha for Organizational Commitment was 0.897. Cronbach's alpha for Job Embeddedness was initially 0.621 but when the item JE6 was removed the value increased to 0.859 ; hence the Job Embeddedness construct is a 7-item scale. 
Table 4: Rotated Component Matrix

\begin{tabular}{|c|c|c|c|c|c|}
\hline & \multicolumn{4}{|c|}{ Component } & \multirow[b]{2}{*}{ A } \\
\hline & 1 & 2 & AVE & $\mathrm{CR}$ & \\
\hline OC5 & .867 & & .629 & .912 & .895 \\
\hline OC4 & .834 & & & & \\
\hline OC9 & .763 & & & & \\
\hline OC7 & .753 & & & & \\
\hline OC8 & .737 & & & & \\
\hline OC6 & .732 & & & & \\
\hline OC3 & .679 & & & & \\
\hline OC10 & .514 & & & & \\
\hline JE2 & & .782 & .527 & .887 & .859 \\
\hline JE4 & & .719 & & & \\
\hline
\end{tabular}

\begin{tabular}{|c|c|c|l|l|l|}
\hline JE9 & & .704 & & & \\
\hline JE3 & & .698 & & & \\
\hline JE7 & & .681 & & & \\
\hline JE8 & & .666 & & & \\
\hline JE1 & & .628 & & & \\
\hline JE5 & & .527 & & & \\
\hline Eigenvalues & 6.593 & $\begin{array}{c}2.33 \\
0\end{array}$ & & & \\
\hline$\%$ of variance & $30.1 \%$ & $\begin{array}{c}25.1 \\
\%\end{array}$ & & & \\
\hline
\end{tabular}

Extraction Method: Principal Component Analysis.

Rotation Method: Varimax with Kaiser Normalization

a. Rotation converged in 3 iterations.

\begin{tabular}{|c|c|c|c|c|c|c|c|c|c|}
\hline \multirow[b]{2}{*}{ Component } & \multicolumn{3}{|c|}{ Initial Eigenvalues } & \multicolumn{3}{|c|}{ Extraction Sums of Squared Loadings } & \multicolumn{3}{|c|}{ Rotation Sums of Squared Loadings } \\
\hline & Total & $\begin{array}{c}\% \text { of } \\
\text { Variance }\end{array}$ & Cumulative $\%$ & Total & $\begin{array}{c}\% \text { of } \\
\text { Variance }\end{array}$ & Cumulative $\%$ & Total & $\begin{array}{c}\% \text { of } \\
\text { Variance }\end{array}$ & Cumulative $\%$ \\
\hline 1 & 6.593 & 41.204 & 41.204 & 6.593 & 41.204 & 41.204 & 4.809 & 30.054 & 30.054 \\
\hline 2 & 2.230 & 13.937 & 55.140 & 2.230 & 13.937 & 55.140 & 4.014 & 25.086 & 55.140 \\
\hline 3 & 1.176 & 7.351 & 62.492 & & & & & & \\
\hline 4 & 1.079 & 6.744 & 69.236 & & & & & & \\
\hline 5 & .829 & 5.182 & 74.418 & & & & & & \\
\hline 6 & .802 & 5.011 & 79.429 & & & & & & \\
\hline 7 & .584 & 3.648 & 83.077 & & & & & & \\
\hline 8 & .495 & 3.092 & 86.169 & & & & & & \\
\hline 9 & .481 & 3.005 & 89.174 & & & & & & \\
\hline 10 & .430 & 2.686 & 91.860 & & & & & & \\
\hline 11 & .337 & 2.109 & 93.969 & & & & & & \\
\hline 12 & .275 & 1.721 & 95.690 & & & & & & \\
\hline 13 & .221 & 1.382 & 97.071 & & & & & & \\
\hline 14 & .183 & 1.145 & 98.216 & & & & & & \\
\hline 15 & .176 & 1.099 & 99.315 & & & & & & \\
\hline 16 & .110 & .685 & 100.000 & & & & & & \\
\hline
\end{tabular}

\section{CONCLUSION AND RECOMMENDATION}

Based on the above analysis to determine the validity and reliability of the instruments, some items that correlates lower with other items were deleted because it reduces the reliability of the scale. After deleting those items the internal consistency reliability increases, thereby making all the remaining items reliable with Cronbach Alpha above the minimum threshold. The implication is that the number of items were reduced from the original numbers, therefore, potential problem areas were detected and handled and the amendments will be implemented in the future research. It is therefore, recommended that the items are reliable and can be used in future researches.

\section{REFERENCE}

[1] Allen, N. J., \& Meyer, J. P. (1990).The measurement and antecedents of affective, continuance and normative commitment to the organization.Journal of Occupational Psychology, 63(1), 118. https://doi.org/10.1111/j.2044-8325.1990.tb00506.x 
[2] Babalola, M. T., Stouten, J., \&Euwema, M. (2016). Frequent change and turnover intention: The moderating role of ethical leadership. Journal of Business Ethics, 134(2), 311-322. doi:10.1007/s10551-014-2433-z

[3] Barlett M.S. (1954). A note on the multiplying factors for various Chi Square Approximations. Journal of the royal statistical society, 16 (1) 296-298

[4] Cadete, L. (2017). What is a pilot study? Tutorials and Fundamentals.https://s4be.cochrane.org/blog/2017/07/31/pilotstudies/

[5] Cesario, F., \& Chambel, M. J. (2017). Linking organizational commitment and work engagement to employee performance. Knowledge and Process Management, 24(2), 152-158. doi:10.1002/kpm.1542.

[6] Da Silva, L. P., Castro, M. A. R., Dos-Santos, M., \&Neto, P. J. d. L. (2018).Commitment to work and its relationship with organizational culture mediated by satisfaction.RevistaBrasileira De Gestão De Negócios, 20(3), 401-420. doi:10.7819/rbgn.v20i3.3947

[7] Dechawatanapaisal, D. (2018). Examining the relationships between HR practices, organizational job embeddedness, job satisfaction, and quit intention. Asia - Pacific Journal of Business Administration, 10(2), 130-148. doi:10.1108/APJBA-11-20170114

[8] Eberman, L., Mazerolle, S. M., Eason, C. M. (2019). Formal and informal work-life balance practices of athletic trainers in collegiate and university settings. Journal of Athletic Training, 54(5), 556-561.

[9] Faloye, D. O. (2014). Organizational Commitment And Turnover Intentions: Evidence From Nigerian Paramilitary Organization. International Journal Of Business \& Economic Development, 2(3), 23-34.

[10] Fontinha, R., Easton, S., Van Laar, D. (2019). Overtime and quality of working life in academics and nonacademics: The role of perceived work-life balance. International Journal of Stress Management, 26(2), 173.

[11] Gorondutse, A. H.(2012) The Influence of Business Social Responsibility (BSR) on Organizational Performances: A Pilot Study. International Journal of Business and Management Tomorrow Vol. 2 No. 12

[12] Hair, J. F., Hult, G. T. M., Ringle, C. M., \&Sarstedt, M. (2014). A Primer on Partial Least squares Structural Equation Modeling (PLS-SEM). Los Angeles: USA: SAGE

[13] Heymann, M. (2010). The impact of demographics on voluntary labour turnover in South Africa.Unpublished MBA dissertation, University of Pretoria, Pretoria.

[14] Holtom, B. C., Mitchell, T. R., \& Lee, T. W. (2006).Increasing human and social capital by applying job embeddednesstheory.Organizational Dynamics, 35(4), 316-331.

[15] Igbaekemen, G. O. \&Idowu, O. A. (2014). Impact Of Organizational Commitment On mployees Productivity: A Case Study Of Nigeria Brewery, Plc. International Journal Of Research In Business Management. 2 (9) 107- 122

[16] Jonathan, P. (2019). Effective Strategies to Increase Employee Commitment and Reduce Employee Turnover.Walden Dissertations and Doctoral Studies Collection. Walden University Scholar Works.

[17] Kaiser, H. F. (1974). An index of factorial simplicity.Psychometrika, 39 (1) 31 -36.

[18] Kwahar, N., \&Iyortsuun, A.S. (2018).Determining the Underlying Dimensions of Quality of Work Life (QWL) in the Nigerian Hotel Industry.Entrepreneurial Business and Economics Review, 6(1), 53-70. https://doi.org/10.15678/EBER.2018.060103

[19] Latham, G. P., Borgogni, L., \&Petitta, L. 2018. Goal setting and performance management in the public sector.Interna-tional Public Management Journal 11(4): 385-403.
[20] Lee, T. W., Mitchell, T. R., Sablynski, C. J., Burton, J. P., \&Holtom, B. C. (2004). The effects of job embeddedness on organizational citizenship, job performance, volitional absences, and voluntary turnover.Academy of Management Journal, 47(5), 711-722.

[21] Lowe, K. N. (2019). What is a pilot study? Editorial.AWHONN, the Association of Women's Health, Obstetric and Neonatal Nurses.

Published by Elsevier Inc.JOGNN, 48, 117-118; https://doi.org/10.1016/j.jogn.2019.01.005

[22] Malhotra, N.K. (2008). Essentials of marketing: An applied orientation (2nd ed.). Australia: Pearson Education

[23] Mallol, C.M., Holtom, B.C., \& Lee, T.W. (2007). Job Embeddedness in a Culturally Diverse Environment, Journal of Business Psychology 22 (1) 35-44 DOI 10.1007/s10869- 0079045

[24] March, J. G., \& Simon, H. A. (1958).Organizations: John Wiley $\&$ Sons Inc.

[25] Mehdi, J. A. Z.,Sharif, M. T., \& Khan I. A. (2021). Increasing Employee Organizational Commitment by Correlating Goal Setting, Employee Engagement and Optimism at Workplace.European Journal of Business and Management. 4 (2) 71-77

[26] Mitchell, T. R., Holtom, B. C., \& Lee, T. W. (2001). How to keep your best employees: Developing an effective retention policy. Academy of Management Executive, 15(4), 96-109.

[27] Mitchell, T. R., Holtom, B. C., Lee, T. W., Sablynski, C. J., \&Erez, M. (2001). Why people stay: Using job embeddedness to predict voluntary turnover. The Academy of Management Journal, 44(6), 1102-1121.

[28] Nunnally, J. C. (1978). Psychometric theory. New York: McGrawHill Inc

[29] Oludayo, O.A., Falola, H.O., Ahaka, O. \&Fatogun, D. (2018).Work-life balance initiative as a predictorof employees' behavioural outcomes. Academic of Strategic Management Journal, 17(1), 1-17

[30] Owolabi, A. B. (2018). Impact of Organisational Culture and Leadership Style on Quality of Work-Life among Employees in Nigeria.African Journal for the Psychological Study of Social Issues, 18(1), 109-121.

[31] Polit, D. F., \& Beck, C. T. (2017). Nursing research: Generating and assessing evidence for nursing practice (10th ed.). Philadelphia, PA: Wolters Kluwer/Lippincott Williams \& Wilkins.

[32] Rusdiyanto, J. (2020). Gaining Leader-Employee Commitment: Linking to Organization Performance in Women Cooperative.Advances in Economics, Business and Management Research, 115 (1) 266-268

[33] Singh, A., \& Gupta, B. (2015). Job Involvement, Organizational Commitment, Professional Commitment, And Team Commitment. Benchmarking: An International Journal, 22(6), 1192-1211. Doi:10.1108/BIJ-01-2014-0007

[34] Sirgy, J.M., Efraty, D., Siegel, P., \& Lee, D. (2001). A new Measure of Quality of Work Life (QWL) Based on Need Satisfaction and Spillover Theories. Social Indicators Research, 55(3), 241-302.

[35] Tabachnick, B.G. \&Fidell, L.S. (2007). Using multivariate statistics (5th ed.). Boston: Pearson Education Inc

[36] Thurstone, L. L. (1947). Multiple-factor analysis; a development and expansion of The Vectors mind. University of Chicago Press

[37] Yousef, D.A. (2017) Organizational Commitment, Job Satisfaction and Attitudes toward Organizational Change: A Study in the Local Government, International Journal of Public Administration, 40:1, 77-88, DOI: 10.1080/01900692.2015.1072217

[38] Zhang, M., Fried, D. D., \&Griffeth, R. W. (2012). A review of job embeddedness: Conceptual, measurement issues, and directions for future research. Human Resource Management Review, 22(3), 220-231. https://doi.org/10.1016/j.hrmr.2012.02.004 